\title{
O ensino fundamental de nove anos e o direito à educação
}

\author{
Lisete Regina Gomes Arelaro \\ Faculdade de Educação da Universidade de São Paulo \\ Márcia Aparecida Jacomini \\ Universidade Federal de São Paulo \\ Sylvie Bonifácio Klein \\ Faculdade de Educação da Universidade de São Paulo
}

\section{Resumo}

Neste artigo são analisadas as consequências das Leis Federais $n^{\circ}$. 11.114/05, que instituiu o início da obrigatoriedade do ensino fundamental aos 6 anos de idade, e a de $n^{\circ} 11.274 / 06$, que ampliou a duração do ensino fundamental para nove anos, mantido o início aos 6 anos. As análises ora apresentadas são baseadas em documentos e dados empíricos da pesquisa Avaliando politicas educacionais: um estudo sobre a implantação do ensino fundamental de nove anos no Estado de São Paulo, de caráter qualitativo, realizada em redes de ensino municipal e estadual, que envolveu diferentes segmentos: profissionais da educação, pais e crianças de 6 anos matriculadas no primeiro ano do ensino fundamental. As entrevistas e os questionários permitiram o levantamento de opiniões dos sujeitos sobre diversos aspectos da implantação do ensino fundamental de nove anos e a comparação com as intenções anunciadas nos documentos oficiais à luz de três princípios educacionais: direito à educação, gestão democrática e qualidade de ensino. Constatou-se a permanência de práticas que desconsideram tanto os preceitos legais quanto a importância da participação dos envolvidos no processo educativo para a realização de uma educação de qualidade. Da mesma forma, o currículo do primeiro ano reflete somente uma adaptação simplista do antigo currículo da primeira série, com pequenas adequações metodológicas que não incorporam o lúdico como específıco da infância. Ficou evidente a insufıciência de recursos materiais e financeiros, a não orientação aos professores, bem como a não discussão do futuro da pré-escola na nova organização escolar.

Correspondência:

Lisete Regina Gomes Arelaro

Avenida da Universidade, $\mathrm{n}^{0} .308$

05508-040 - São Paulo/SP

E-mail: liselaro@usp.br

\section{Palavras-chave}

Política educacional - Ensino fundamental de nove anos Direito à educação - Gestão democrática - Qualidade de ensino. 


\section{Nine-year fundamental education and the right to education}

Lisete Regina Gomes Arelaro

University of São Paulo

Márcia Aparecida Jacomini

Federal University of São Paulo

Sylvie Bonifácio Klein

University of São Paulo

Contact:

Lisete Regina Gomes Arelaro

Avenida da Universidade, $n^{\circ} .308$

05508-040 - São Paulo/SP

E-mail: liselaro@usp.br

\section{Abstract}

This article investigates the consequences of the Federal Laws No. 11114/05, which instituted the start of the period of mandatory education at the age of six, and No. 11274/06, which increased the duration of fundamental education to nine years, keeping its start at the age of six. The analyses presented here are based on documents and empirical data of the study Avaliando politicas educacionais: um estudo sobre a implantação do ensino fundamental de nove anos no Estado de São Paulo [Evaluating educational policies: a study of the implementation of nine-year fundamental education in the State of São Paulo]. Under a qualitative approach, that study was conducted in municipal and state public school systems, and involved different segments: education workers, parents, and six-year-olds enrolled at the first year of fundamental education. The interviews and questionnaires helped to gather their opinions on various aspects of the implementation of nine-year fundamental education, and allowed the comparison with the intentions declared in the official documents in the light of three educational principles: the right to education, democratic management, and quality of education. It was observed that practices remain which disregard both the legal precepts and the importance of the participation of those involved in the education process in order to achieve quality education. Likewise, the first year curriculum reflects only a simplistic adaptation of the former first year curriculum, with minor methodological adjustments that do not incorporate the ludic as something specific to childhood. It became evident that material and financial resources are insufficient, that teachers are not being oriented, and that the future of pre-school under the new organization is not being discussed.

\section{Keywords}

Educational policy - Nine-year fundamental education - Right to education - Democratic management - Quality of education. 
Neste artigo são analisados e discutidos os desdobramentos das Leis Federais n ${ }^{\circ}$. 11.114/05, que instituiu o início da obrigatoriedade do ensino fundamental aos 6 anos de idade, e no. 11.274/06, que ampliou a duração do ensino fundamental para nove anos, mantido o início aos 6 anos de idade. As considerações ora apresentadas são baseadas em documentos e dados empíricos de pesquisa intitulada Avaliando políticas educacionais: um estudo sobre a implantação do ensino fundamental de nove anos no Estado de São Paulo, realizada por grupo de pesquisa na Faculdade de Educação da Universidade de São Paulo entre os anos de 2006 e 2009.

0 objetivo principal da pesquisa foi a realização de estudo exploratório sobre a implementação do ingresso de crianças de 6 anos nas escolas de ensino fundamental de oito e de nove anos de duração, nas redes de ensino municipal de São Paulo e de Suzano e na rede estadual de São Paulo, analisando as mudanças ocorridas na dinâmica das escolas com a implementação das leis.

0 estudo, de caráter qualitativo, contou com análise documental que fundamentou as propostas governamentais sobre o ensino fundamental de nove anos e com as orientações para a efetivação dessa política nas três redes de ensino estudadas. A pesquisa de campo foi realizada em seis escolas: duas escolas da rede estadual, três da rede municipal de São Paulo e uma da rede municipal de Suzano. Os dados foram coletados por meio de entrevistas e questionários com os diferentes segmentos dos profissionais da educação e com pais e crianças de 6 anos matriculadas no primeiro ano do ensino fundamental.

Foram realizadas entrevistas com 57 crianças de 6 anos, seis gestores e quatro professoras de primeiro ano. Foram utilizados questionários semiestruturados nas entrevistas com professoras de primeiros anos e gestores, e técnicas de grupo focal com as crianças. Com pais e professores dos demais anos do ensino fundamental, foram aplicados questionários contendo perguntas abertas e fechadas, contabilizando-se respostas de 46 pais e 59 professores.
As entrevistas e os questionários permitiram o levantamento de opiniões dos sujeitos da pesquisa sobre diversos aspectos da implantação do ensino fundamental de nove anos e a comparação com as intenções anunciadas nos documentos oficiais.

A pesquisa foi realizada logo após a aprovação das leis, em período transitório para a reorganização das redes de ensino, que tiveram até o ano de 2010 para adequar a duração da etapa de ensino fundamental sob sua responsabilidade. As redes pesquisadas apresentaram situações diferenciadas na forma de realizar o proposto nas leis. As redes estadual e municipal de São Paulo implantaram a matrícula das crianças de 6 anos logo após a homologação das leis, porém a alteração da duração do ensino fundamental para nove anos foi postergada para o ano de 2010. $\mathrm{Na}$ rede municipal de Suzano, houve a implementação imediata das duas leis federais: o último ano da educação infantil passou a ser denominado Série Inicial Municipal (SIM), e as crianças continuaram na escola de educação infantil. Nesse município existiam poucas unidades escolares onde se atendiam ensino fundamental e educação infantil, chamadas Escolas Municipais de Educação Infantil e Ensino Fundamental (EMEIFs). Com a implementação do ensino fundamental de nove anos e a permanência das crianças de 6 anos nas escolas em que já estudavam (inclusive com os mesmos professores), todas as Escolas Municipais de Educação Infantil passaram a se denominar EMEIFs.

Os dados recolhidos na pesquisa de campo e o levantamento de dados estatísticos junto ao Instituto Nacional de Estudos e Pesquisas Educacionais Anísio Teixeira (Inep), associados à bibliografia específica, permitiram discutir as mudanças na organização da educação básica à luz de três princípios educacionais: direito à educação, gestão democrática e qualidade de ensino.

Um dos aspectos considerados refere-se à motivação que levou à alteração da organização escolar do ensino fundamental. Teriam sido aspectos pedagógicos e educacionais? Pressão da sociedade 
contemporânea em busca de efetivar o direito à educação? Atendimento às recomendações internacionais? Ou questões de ordem financeiro-contábil que compensassem a esfera municipal das novas responsabilidades assumidas no processo de municipalização do ensino fundamental?

\section{Por que o ensino fundamental de nove anos?}

É fato que, desde os anos 70 do século passado, fundamentados nas teorias "compensatórias”, programas foram organizados no sentido de possibilitar que as crianças - em especial as oriundas de setores socioeconomicamente carentes - frequentassem um ano de pré-escola para irem se "ambientando" com as exigências que lhes seriam feitas na série inicial do ensino fundamental, quando o processo de alfabetização formal e sistemático se inicia. "Habituar" as crianças a sentar-se em carteiras e mesinhas, ter familiaridade com brinquedos pedagógicos com letras e números, ter disciplina, concentração e organização, enfim, preparar-se "culturalmente" para o início do trabalho alfabetizador, "compensando" suas defasagens socioculturais, eram seus objetivos principais.

No entanto, o caráter compensatório atribuído à pré-escola na década de 1970 foi sendo revisto à luz da construção de uma identidade da educação infantil como etapa da educação básica, não se vinculando somente à preparação das crianças para o início ou consolidação da alfabetização no ensino fundamental (Corrêa, 2002; Campos, Rosemberg, Ferreira, 1992). Tal identidade se consolidou no reconhecimento do direito à educação das crianças de 0 a 6 anos, expresso na Constituição Federal de 1988 (CF/88) e na Lei de Diretrizes e Bases da Educação Nacional de 1996 (LDB/96).

0 argumento predominante nas justificativas do Ministério da Educação (MEC) e na documentação legislativa sobre o ensino fundamental de nove anos é que a medida garante a ampliação do direito à educação para as crianças de 6 anos de idade, em especial as pobres e exclu- ídas do sistema educacional. Ponderou-se, naquele momento, que as crianças de 6 anos das classes média e alta já estavam matriculadas em escolas e que seria necessário incluir as classes desfavorecidas. A consideração de que as crianças de 6 anos ainda estavam fora da escola, seja pela não obrigatoriedade ou por não existir oferta de vagas suficientes na educação infantil pública, gerou um aparente consenso de que o ensino fundamental de nove anos garantiria um maior número de alunos matriculados nas escolas brasileiras e, portanto, asseguraria a essas crianças a efetivação do seu direito à educação.

Na legislação e nos documentos orientadores da implantação dessa política, é possível encontrar diversos textos que reforçam tal argumentação. No documento do MEC "Orientações para inclusão das crianças de seis anos”, Anelise Monteiro do Nascimento afirma em seu texto que

[...] podemos ver o ensino fundamental de nove anos como mais uma estratégia de democratização e acesso à escola. A Lei n ${ }^{\circ}$. 11.274, de 6 de fevereiro de 2006, assegura o direito das crianças de seis anos à educação formal, obrigando as famílias a matriculá-las e o Estado a oferecer o atendimento. (Brasil, 2007, p. 27)

Patricia Corsino corrobora essa ideia ao apresentar o ensino fundamental de nove anos como uma oportunidade histórica para as crianças de 6 anos das classes populares frequentarem a escola:

[...] a ampliação do ensino fundamental para nove anos, que significa bem mais que a garantia de mais um ano de escolaridade obrigatória, é uma oportunidade histórica de a criança de seis anos pertencente às classes populares ser introduzida a conhecimentos que foram fruto de um processo sócio-histórico de construção coletiva. (Brasil, 2007, p. 61-62)

Essa argumentação parte de pressupostos nem sempre condizentes com a legislação vigente. 0 primeiro é de que a criança de 6 anos não 
teria assegurado seu direito à educação, uma vez que se encontra na educação infantil, etapa considerada não obrigatória. De acordo com a $\mathrm{CF} / 88$, art. 208, é dever do Estado e direito das crianças e das famílias a matrícula na educação infantil (em creches e pré-escolas). Portanto, nos termos da lei, o direito das crianças à educação formal, desde seu nascimento, está garantido. Se o governo reconhece que as instituições de educação infantil não ofertam vagas suficientes para atender a estas crianças, a consequência lógica seria o estímulo técnico-financeiro para que os municípios assumissem sua responsabilidade constitucional. No entanto, a opção foi por uma política nacional de novo lócus de estudo dessa criança, uma transferência de etapa de ensino que significou uma mudança radical de diversos aspectos no atendimento.

Segundo documento do próprio MEC (Brasil, 2004a), já em 2000, cerca de 80\% das crianças na faixa etária dos 6 anos estavam matriculadas em alguma instituição escolar. Dessas, aproximadamente $48 \%$ o faziam na educação infantil, 36\% no ensino fundamental e 16\% em classes de alfabetização.

Em relação a esses dados, é necessário considerar o elemento indutor da municipalização do ensino fundamental, em especial das séries iniciais, promovido pela política de fundos para o financiamento da educação brasileira a partir de 1998, com a criação do Fundo de Manutenção e Desenvolvimento do Ensino Fundamental e Valorização do Magistério (Fundef) por meio da Emenda Constitucional n ${ }^{\circ}$. 14/96.

Esse fundo pretendeu valorizar o ensino fundamental com a criação de fundos estaduais sustentados com a vinculação de 15\% dos 25\% constitucionalmente obrigatórios para a manutenção e desenvolvimento do ensino, estabelecendo um sistema de "retribuição pecuniária" aos estados e municípios correspondente ao número de crianças matriculadas no ensino fundamental em cada rede pública.

Esse mecanismo incentivou dois movimentos concomitantes: primeiro, a aceleração do processo de municipalização do ensino fundamental, principalmente nos municípios mais pobres; e segundo, o aumento médio do número de alunos em cada turma, uma vez que esse procedimento constitui uma das formas mais econômicas de atender a um maior número de alunos com o menor custo, até porque foram raras as implementações de planos de construções escolares ousados, que previssem a regularização do atendimento escolar nas redes públicas em funcionamento a partir de uma relação pedagógica ideal de professor/número de alunos/número de turmas (Arelaro, 2007).

É necessário atentar para o fato de que o processo de municipalização do ensino fundamental, considerado o ano de 2006, já havia provocado um aumento significativo das matrículas nas redes municipais de ensino, uma vez que $60 \%$ dos atendimentos públicos nessa etapa estavam municipalizados e, do total das matrículas de $1^{\text {a }}$ a $4^{\text {a }}$ série, $75 \%$ delas já estavam sob responsabilidade municipal, e somente 25\% sob a estadual ${ }^{1}$.

Em função desses dados, é pertinente considerar que a proposta da redução da idade de matrícula no ensino fundamental para 6 anos passou a ser gestada a partir da consolidação do processo de municipalização, quando então os municípios se conscientizaram de que o custo real desse processo era muito mais alto do que o indicado pelas projeções financeiro-contábeis iniciais. Soma-se a esse fato a exclusividade de financiamento para o ensino fundamental com os recursos do Fundef.

Assim, a matrícula das crianças de 6 anos no ensino fundamental, que se inicia em algumas redes de ensino antes das Leis Federais $n^{\circ}$. 11.114/05 e no ${ }^{\circ}$ 11.274/06, pode também ser compreendida no marco do Fundef.

Além disso, o amparo legal para a matrícula de crianças de 6 anos na $1^{\text {a }}$ série do ensino fundamental estava previsto na $\mathrm{LDB} / 96$, no art. 87, desde que houvesse vagas disponíveis. Já na

1. Fonte: Inep. Sinopse estatística, 2006. 
Lei Federal $n^{\circ}$. 5.692/71 essa possibilidade pode ser constatada no art. 19, e em diferentes atos legais que estabeleciam critérios para "acomodação da demanda escolar", ainda que em caráter excepcional, mantidos os 7 anos de idade como marco inicial do processo de escolarização formal.

No início dos anos 2000, surgem propostas de dirigentes educacionais, por intermédio da União dos Dirigentes Municipais de Educação (Undime) e do Conselho Nacional de Secretários Estaduais de Educação (Consed), visando minimizar o impacto do Fundef nas demais etapas da educação básica caso novas alternativas não fossem implementadas no sentido de reduzir a demanda reprimida da educação infantil, da educação de jovens e adultos e do ensino médio (Costa, 2000).

Já era previsto que a maioria dos municípios pobres, com destaque aos da Região Nordeste, não teria condições de oferecer educação infantil para além de um ano, ou seja, para além das chamadas "classes de alfabetização", que já funcionavam como classes de educação pré-escolar e tinham por objetivo "preparar as crianças para o processo escolar propriamente dito da alfabetização, no ensino fundamental" (Costa, 2000, p. 34).

Cabe mencionar a experiência dos ciclos de formação iniciada em Belo Horizonte e realizada de forma exitosa em Porto Alegre (Escola Plural e Escola Cidadã, nos anos 1990), em que a organização do ensino fundamental em três ciclos de três anos cada pressupunha a entrada das crianças de 6 anos no primeiro ano dessa etapa de ensino (Azevedo, 2007; Arroyo, 1999).

As medidas adotadas no início do século XXI foram de três ordens: a primeira, a disposição, no Plano Nacional de Educação (PNE - Lei $n^{\circ}$. 10.172/01), da possibilidade de matrícula aos 6 anos de idade, na $1^{\text {a }}$ série do ensino fundamental, combinada com a convicção de manutenção mais longa do Fundef. A segunda, o Fundo de Manutenção e Desenvolvimento da Educação Básica e Valorização dos Profissionais de Educação (Fundeb) - consubstanciado na EC $n^{0} .53 / 2006$-, que, abrangendo todas as modalidades e etapas de educação básica, acabaria com a exclusividade de financiamento do ensino fundamental. A nova extensão do financiamento não parece ter sido considerada na proposta de reorganização do ensino fundamental, mesmo que sua proposição tenha se iniciado em 1999, ainda com o Fundef em vigor. A terceira, a Emenda Constitucional $n^{\circ} .59 / 2009$, considerando obrigatória, a partir de 2016, a educação dos 4 aos 17 anos de idade. Essas três variáveis construíram um cenário contraditório não só para a educação infantil, mas também para a nova organização do ensino fundamental.

Tal emenda foi defendida inicialmente pelas entidades científıcas e associativas da educação por se tratar do fim progressivo da Desvinculação de Receitas da União (DRU) na área da educação e por gerar a expectativa de correspondente aumento de recursos financeiros para essa área social. Entretanto, como medida de negociação, a ampliação da escolaridade obrigatória foi introduzida na EC e aprovada sumariamente, sem a necessária discussão para uma mudança de tal porte.

0 Fundeb incluiu todas as etapas e modalidades da educação básica, tendo sido mantido o mesmo padrão de distribuição equitativa do Fundef, agora vinculando 20\% dos principais impostos que compõem os $25 \%$ de recursos constitucionalmente destinados à manutenção e desenvolvimento do ensino.

No entanto, a Lei ${ }^{\circ}$. 11.494/07, que regulamentou o Fundeb, manteve a equação da Lei n ${ }^{\circ}$. 9.424/96, que regulamentava o Fundef, qual seja: a um maior número de alunos atendidos, corresponde um maior volume de recursos recebidos pela esfera pública respectiva. Essa fórmula possui uma lógica perversa, pois se esse "quociente" for ampliado de forma substantiva, ou seja, se estados e municípios matricularem um número significativamente maior de alunos que em anos anteriores, o valor aluno/ano poderá ser menor, uma vez que o cálculo é feito considerando exclusivamente 0 número de alunos matriculados no ano anterior em cada modalidade ou etapa do ensino.

Comprovando esta lógica, a fórmula aprovada para os anos de $2007 / 2008$, para as 
diferentes etapas e modalidades de educação básica, valorizou financeiramente mais os anos iniciais do ensino fundamental do que a educação em creches e pré-escolas, o que, evidentemente, acaba estimulando a matrícula cada vez mais antecipada das crianças pequenas nas séries iniciais do ensino fundamental. 0 fator de ponderação para a distribuição dos recursos de acordo com o número de matrículas era menor em 10\% para a pré-escola. Isso significava que o sistema de ensino recebia, para a mesma criança de 6 anos matriculada na pré-escola, 10\% a menos do que receberia se ela estivesse matriculada no ensino fundamental ${ }^{2}$. Pode-se dizer, portanto, que essa é uma política de incentivo que visa aumentar as matrículas nesta modali- dade em detrimento das matrículas na educação infantil. Acrescente-se as especificidades dessa faixa etária, que recomendam que as classes/ turmas de educação infantil sejam constituídas, no caso das crianças de 6 anos, com 20 alunos (Parecer CNE/CEB nº. 22/98; Brasil, 2009).

Uma observação atenta do número de matrículas do ensino fundamental no Brasil, independente da duração de oito e ou de nove anos, no período de 2004 a 2009 (Tabela I), mostra uma redução no número total de atendimento de alunos no ensino fundamental de mais de dois milhões, o que permite afırmar que, apesar de incorporar um ano de pré-escola, o número de atendimento não aumentou com o ensino fundamental de nove anos.

Tabela 1 - Número de matrículas no ensino fundamental de 8 e 9 anos no Brasil

\begin{tabular}{|c|c|c|c|c|c|}
\hline \multirow[b]{3}{*}{ Brasil } & \multirow[b]{3}{*}{ Total } & \multicolumn{4}{|c|}{ Matrículas no Ensino Fundamental } \\
\hline & & \multicolumn{2}{|c|}{ EF 8 anos } & \multicolumn{2}{|c|}{ EF 9 anos } \\
\hline & & Rede pública & Rede privada & Rede pública & Rede privada \\
\hline 2004 & 34.012 .434 & 23.384 .918 & 3.229 .388 & 7.296 .036 & 102.092 \\
\hline 2005 & 33.534 .561 & 22.854 .792 & 3.245 .270 & 7.982 .320 & 131.499 \\
\hline 2006 & 33.282 .663 & 19.763 .812 & 2.853 .236 & 10.050 .874 & 614.741 \\
\hline 2007 & 32.122 .273 & 16.367 .891 & 1.534 .138 & 12.560 .714 & 1.659 .530 \\
\hline 2008 & 32.086 .700 & 14.208 .026 & 1.246 .645 & 14.260 .670 & 2.371 .359 \\
\hline 2009 & 31.705 .528 & 12.008 .613 & 986.359 & 15.918 .526 & 2.792 .030 \\
\hline
\end{tabular}

Observa-se também que, a partir de 2007, há, nacionalmente, uma ampliação das matrículas no ensino fundamental com duração de nove anos (rede pública), tornando-se equivalente ao de oito anos em 2008 e maioria em 2009. 0 mesmo não ocorre no Estado de São Paulo, que, em 2009, tinha apenas 26,4\% das matrículas no ensino fundamental de nove anos, apresentando pequeno aumento - cerca de 200 mil alunos - nas matrículas totais, considerado o período de 2004 a 2009.
Na rede privada, porém, o Estado de São Paulo segue a tendência nacional, com uma abrupta inversão no ano de 2007, quando as matrículas no ensino fundamental de nove anos praticamente triplicaram, passando de cerca de 600 mil para mais de 1,6 milhão de alunos em nível nacional (Tabela 1) e de 61 mil para 460 mil no Estado de São Paulo (Tabela 2).

2. A partir de 2010 , os fatores de ponderação para pré-escola urbana em tempo parcial e ensino fundamental são semelhantes, ou seja, 1,00 (Portaria MEC nº.777, de 10/08/2009). 
Tabela 2 - Número de matrículas no ensino fundamental de 8 e 9 anos no Estado de São Paulo

\begin{tabular}{c|c|c|c|c|c}
\hline \multicolumn{7}{c}{ Matrículas no Ensino Fundamental } \\
\hline \multirow{2}{*}{$\begin{array}{c}\text { Estado de } \\
\text { São Paulo }\end{array}$} & \multirow{2}{*}{ Total } & Rede pública & Rede privada & Rede pública & Rede privada \\
\hline 2004 & 5.825 .079 & 5.041 .124 & 783.955 & 36.445 & 1.431 \\
\hline 2005 & 5.875 .983 & 4.968 .204 & 791.717 & 114.404 & 1.658 \\
\hline 2006 & 6.014 .209 & 4.946 .062 & 756.965 & 249.366 & 61.816 \\
\hline 2007 & 6.017 .579 & 4.779 .731 & 368.708 & 408.187 & 460.953 \\
\hline 2008 & 6.030 .171 & 4.489 .788 & 218.373 & 658.971 & 662.648 \\
\hline 2009 & 6.057 .884 & 3.793 .479 & 148.273 & 1.359 .996 & 756.136 \\
\hline
\end{tabular}

Fonte: Inep - Sinopse estatística para os anos de 2004 a 2009 .

Diante disso, pode-se dizer que a política adotada pelos governos do estado e do município de São Paulo implicou a perda de um ano de escolarização para as crianças que ingressaram aos 6 anos no ensino fundamental de oito anos, já que elas deixaram de frequentar um ano na educação infantil e não tiveram a duração do seu curso de ensino fundamental ampliada.

\section{Implantação do ensino fundamental de nove anos:}

os sujeitos e os caminhos percorridos

Embora garantida na legislação, a prática da gestão escolar nem sempre considera os elementos básicos da gestão democrática: a participação e a tomada de decisão de forma coletiva, garantindo a manifestação das diferentes opiniões. Em relação à gestão da escola, muitas vezes, a participação, especialmente a de pais e alunos, nas instâncias de discussão e decisão é meramente formal. Não raro os pais e os alunos e, em alguns casos, também os professores são informados, e não consultados, sobre as questões educacionais que lhes dizem respeito.

No âmbito das políticas educacionais federal, estadual e municipal, o expediente da democracia representativa normalmente é o mais adequado, dada a impossibilidade de se fazer consulta direta à população sobre cada política que os governos se propõem a implantar (Benevides, 1994; Bobbio, 2000).

Assim, colocar em prática o princípio da gestão democrática no âmbito do governo federal pressupõe debater as políticas educacionais nacionais com os entes federados (órgãos estaduais e municipais de educação) e organizações representativas da sociedade civil na perspectiva de incorporação das diversas posições para a construção de consensos ou decisões pela maioria.

Em relação aos governos estaduais e municipais, uma gestão democrática pressupõe a mesma sistemática, ou seja, o debate das políticas com a participação, em diferentes níveis, da comunidade escolar e das organizações que representam os diversos setores da sociedade civil. Cabe ouvir, debater, convencer ou consensuar, admitindo e incorporando a diversidade.

Dado que a meta de ampliação do ensino fundamental para nove anos expressa no PNE/2001 era prerrogativa da União, esperava-se que no período de 2001 a 2005 o governo federal tivesse realizado amplos debates com a comunidade educacional acerca de sua implementação. Entretanto, os dados divulgados pelo MEC acerca da participação dos estados e municípios nas discussões sobre o ensino fundamental 
de nove anos indicam que essa política educacional não foi discutida com a maioria dos municípios brasileiros, justamente os principais entes federados responsáveis pela educação infantil e primeiros anos do ensino fundamental.

No documento "Ampliação do ensino fundamental para nove anos: relatório do Programa”, de 2004, o MEC divulgou dados de sete encontros regionais com estados e municípios para discutir como implementar a ampliação do ensino fundamental para nove anos. De acordo com o documento,

[...] uma consulta feita pela SEB/MEC em 2003 mostrou que, apesar do interesse de muitas secretarias em ampliar o Ensino Fundamental para nove anos, elas aguardavam definições sobre recursos financeiros e outros aspectos para tomar esta decisão. (Brasil, 2004b, p. 3)

Naquele momento, a discussão sobre a ampliação da obrigatoriedade do ensino já estava definida em torno do ensino fundamental de nove anos, com a matrícula obrigatória aos 6 anos de idade. Não há menção sobre a intenção ou a possibilidade de tornar obrigatório o último ano da educação infantil, onde grande parte das crianças de 6 anos já estava matriculada.

Tratava-se de discutir como implementar uma política já defınida tal como a Secretaria de Educação Básica (SEB) do MEC apresentou no documento. Os encontros regionais realizados em fevereiro de 2004 tiveram esse caráter, como pode ser verificado nos objetivos dos encontros:

a) Trazer para estudo conjunto dos dirigentes e técnicos do Ministério da Educação, dos estados e dos municípios, as questões centrais que envolvem a ampliação do Ensino Fundamental, considerando as crianças de seis anos de idade como novos sujeitos da escolaridade formal obrigatória.

b) Promover o conhecimento e o intercâmbio de experiências bem-sucedidas durante o processo de ampliação do Ensino Fundamental para nove anos. c) Apresentar e aperfeiçoar a proposta de acompanhamento e avaliação dessa iniciativa. (Brasil, 2004, p. 3)

Evidentemente que essa iniciativa é importante na preparação das redes de ensino para a realização do ensino fundamental de nove anos. No entanto, é preciso saber em que medida os sistemas de ensino se apropriaram das orientações do MEC, principalmente as apresentadas na publicação Ensino fundamental de nove anos: orientações para a inclusão da criança de seis anos de idade (Brasil, 2007), ou construíram suas próprias, baseadas nessas orientações.

Nesse documento, publicado pelo MEC três meses após a promulgação da Lei $n^{\circ}$. 11.274/06, há orientações para os sistemas ou redes de ensino realizarem a adequação do currículo escolar, tendo em vista contemplar os propósitos do ensino fundamental de nove anos, e oferecerem formação e diretrizes aos professores que trabalharão com as crianças de 6 anos, considerando as especificidades e demandas da idade.

Outro aspecto que chama a atenção em relação à gestão democrática diz respeito à participação dos estados e municípios e das entidades da sociedade civil em termos numéricos. Conforme documento do MEC:

Desses encontros participaram 247 secretarias de educação que, em 2003, haviam manifestado interesse na ampliação imediata: quatro estaduais - Amazonas, Distrito Federal, Goiás e Sergipe - e 243 municipais.

Participaram, ainda, dos encontros regionais representantes da União dos Dirigentes Municipais de Educação (UNDIME) e do Conselho Nacional de Educação (CNE), secretários estaduais e municipais de educação, equipes técnicas das secretarias de educação, diretores de escola, professores da Educação Infantil e do Ensino Fundamental, supervisores e inspetores de ensino, orientadores pedagógicos e outros profissionais da educação. (Brasil, 2004b)

A despeito da informação de que se tratavam de secretarias de educação que haviam 
manifestado, no ano anterior, interesse na ampliação imediata do ensino fundamental, cabe refletir sobre a pequena participação dos estados e municípios nesse processo. Dado que o Brasil tem 5.564 municípios, pode-se afirmar que o número de participantes é muito pequeno em termos de representatividade. De acordo com o documento, nove secretarias municipais de educação do Estado de São Paulo participaram dos encontros. Como o Estado de São Paulo tem 645 municípios, participaram apenas 1,4\% dos órgãos municipais, e não os com maior densidade populacional.

Constatada essa situação, na pesquisa de campo buscamos saber em que medida essas orientações da SEB/MEC estavam sendo contempladas nas redes de ensino estudadas.

De acordo com os dados dos questionários respondidos pelos professores, verificou-se que eles tinham conhecimento da Lei $n^{\circ}$. 11.274/06. No entanto, a maioria afırmou não ter participado de discussões sobre o ensino fundamental de nove anos ou ter recebido orientações sobre como trabalhar com as crianças de 6 anos. Isso foi confirmado pelas professoras entrevistadas.

Embora a pesquisa tenha sido realizada em período anterior (2006-2009) ao prazo final para a implantação do ensino fundamental de nove anos (2010), chama a atenção o fato de que as redes de ensino não realizaram discussão a contento, mesmo tendo matriculado crianças de 6 anos no ensino fundamental, e também não ofereceram orientações sobre o tema de forma suficiente, conforme depoimento das professoras que participaram da pesquisa.

Não participei, na verdade eu fui buscar todas as informações por conta própria. Praticamente não houve comentário nenhum, a única discussão que aconteceu foi por minha iniciativa quando no ano de 2006 eu peguei uma sala de $1^{\text {a }}$ série, na qual todos tinham seis anos. (Professora da rede estadual paulista)

Embora 80\% dos pais tenham afirmado que sabiam que, a partir de 2006, as crianças de 6 anos deveriam ser matriculadas no ensino fundamental, a quase totalidade disse não ter sido consultada ou ter recebido orientações sobre a reorganização dessa etapa de ensino. As crianças entrevistadas disseram não ter conversado ou recebido explicações de seus professores, da diretora ou da coordenadora pedagógica da escola sobre a nova organização do ensino fundamental. Embora com opiniões divididas entre a preferência pela escola de educação infantil e a escola de ensino fundamental, a maioria das crianças disse ressentir-se da falta das brincadeiras e espaços que eram característicos da educação infantil.

A [escola] do prezinho é mais legal porque aqui não tem brinquedo pra brincar, gangorra, essas coisas, e no prezinho é legal. (Criança do $1^{\circ}$ ano de uma escola municipal de São Paulo) Eu gosto das duas [escolas], mas eu gosto mais da pré-escola porque lá tem um monte de coisa para a gente brincar. Tem brinquedo, tem dia do brinquedo, tem um parquinho cheio de areia que a gente pode construir castelinho, tem escorregador. (Criança da $1^{\text {a }}$ série de escola estadual no município de Suzano)

Os depoimentos mostraram a quase ausência de espaços de discussão para debaterem e opinarem sobre o ensino fundamental de nove anos. Verificou-se, também, que houve pouca orientação aos professores para a implementação dessa política, o que pode levar a uma "pedagogia do fato consumado" que descaracteriza a proposta e compromete a qualidade do ensino oferecida aos alunos de 6 anos.

Essa dinâmica de implementação das políticas educacionais, como já analisou Neusa Ambrosetti (1990) ao estudar a implementação do ciclo básico de alfabetização na rede estadual de São Paulo, pode comprometer os propósitos dessa política, na medida em que os professores não são consultados ou orientados a contento.

Colocados como executores de reformas e programas oficiais que não entendem, não 
aceitam e para cuja elaboração não foram ouvidos, os professores têm atravessado essas mudanças adotando uma atitude que poderíamos definir como "pedagogia do possível", ou seja, atendem formalmente às exigências oficiais, acrescentam à sua prática aquilo que julgam conveniente, e continuam trabalhando a sua maneira. (Ambrosetti, 1990, p. 58)

Do ponto de vista da gestão democrática, constatou-se a permanência de práticas que desconsideram tanto os preceitos legais quanto a importância da participação dos envolvidos no processo educativo para a realização de uma educação de qualidade. Ainda prevalece a implementação pela força da lei, em detrimento do debate, do convencimento e de orientações que fundamentam a realização dos propósitos educacionais.

\section{Direito à educação, reprovação escolar e qualidade do ensino}

Após a quase universalização do ensino fundamental na faixa etária dos 7 aos 14 anos e a relativa ampliação do acesso ao ensino médio ocorridas no final do século XX e início do XXI, a temática da qualidade da educação ganhou visibilidade no cenário educacional brasileiro, tornando-se assunto recorrente entre os educadores, a comunidade escolar, a imprensa e a academia.

Grosso modo, as discussões sobre a qualidade da educação aparecem vinculadas à divulgação do baixo desempenho dos alunos nas avaliações externas e às políticas de não reprovação anual adotadas por algumas redes de ensino.

A vinculação de um ensino de qualidade às práticas de reprovação e exclusão escolares continua penalizando os historicamente excluídos e cria uma falsa ideia sobre a qualidade do ensino. Isso porque se aceita que uma escola de qualidade é aquela que promove apenas os alunos que conseguem galgar níveis de conhecimentos socialmente aceitos, a despeito da atuação da escola e de sua condição de vida. Em relação aos demais, admite-se que, pelos mais diferentes motivos, não são capazes de se apropriar dos conhecimentos e da cultura que são selecionados para serem trabalhados na escola, ficando, portanto, impossibilitados de usufruir do direito à educação.

A tendência de responsabilizar as escolas, os professores e a progressão continuada pelo baixo desempenho escolar dos alunos, anunciada por muitos governos e incentivada pela grande imprensa, tira de foco as principais causas da má qualidade do ensino e dificulta a construção de uma concepção de qualidade social de educação para todos que supere a dicotomia entre a chamada boa qualidade da escola de antigamente e a má qualidade da escola atual (Jacomini, 2010).

A partir dos documentos relativos ao ensino fundamental de nove anos e dos dados da pesquisa de campo, é interessante pensar como tem sido conduzida essa ampliação da escolaridade obrigatória nos aspectos relacionados à qualidade do ensino oferecido às crianças de 6 anos nas escolas de ensino fundamental.

A LDB/96 estabelece que o dever do Estado com a educação escolar deve ser efetivado mediante, entre outros aspectos, "padrões mínimos de qualidade de ensino, definidos como a variedade e quantidade mínimas, por aluno, de insumos indispensáveis ao desenvolvimento do processo de ensino-aprendizagem" (art. 4º, IX). Disso decorre que cada política de Estado para a educação deve considerar o oferecimento das condições para que ela seja efetivada de forma a atingir os objetivos anunciados.

Em relação ao ensino fundamental de nove anos, o documento Ensino fundamental de nove anos: passo a passo do processo de implantação, do MEC, anuncia os objetivos e os propósitos dessa política educacional da seguinte forma:

Com essa medida, o Estado reafirma o Ensino Fundamental como direito público subjetivo, estabelecendo a entrada das crianças de seis anos de idade no ensino obrigatório, garantindolhes vagas e infraestrutura adequada. 
Os objetivos da ampliação do ensino fundamental para nove anos de duração são: a)- melhorar as condições de equidade e de qualidade da Educação Básica, b)- estruturar um novo ensino fundamental para que as crianças prossigam nos estudos, alcançando maior nível de escolaridade; c)- assegurar que, ingressando mais cedo no sistema de ensino, as crianças tenham um tempo mais longo para as aprendizagens da alfabetização e do letramento. (Brasil, 2009, p. 5, grifo nosso)

No mesmo documento, o MEC estabelece alguns princípios que devem ser considerados pelos estados e municípios na implementação do ensino fundamental de nove anos.

a) Promoção da autoestima dos alunos no período inicial de sua escolarização;

b) 0 respeito às diferenças e às diversidades no contexto do sistema nacional de educação, presentes em um país tão diversificado e complexo como o Brasil; c) A não aplicação de qualquer medida que possa ser interpretada como retrocesso, o que poderia contribuir para o indesejável fracasso escolar;

d) Os gestores devem ter sempre em mente regras de bom senso e de razoabilidade, bem como tratamento diferenciado sempre que a aprendizagem do aluno o exigir. (Brasil, 2009, p. 13, grifo nosso)

Diante desses objetivos e princípios, poderíamos perguntar: em que medida estados e municípios os têm considerado no processo de implantação do ensino fundamental de nove anos? Segundo reportagem da Folha de S. Paulo, em 23/02/2010, constata-se, a partir de dados ainda não oficializados pelo MEC, que, em 2009, cerca de 80 mil crianças de 6 anos foram reprovadas no Brasil.

Esse número, apesar de ter causado impacto na imprensa e nos movimentos de educação, apenas segue tendência existente já em anos anteriores, conforme pode ser observado na Tabela 3:

Tabela 3 - Número de alunos reprovados no 1ํㅡㅅㅡo do EF de 9 anos - Brasil

\begin{tabular}{c|c|c|c|c|cc}
\hline \multicolumn{7}{c}{ Número de alunos reprovados no 10 ano do EF de nove anos - Brasil } \\
\hline 2003 & 2004 & 2005 & 2006 & 2007 & 2008 & 2009 \\
\hline 18.326 & 29.989 & 42.964 & 74.096 & 74.471 & $71673^{\star}$ & $79300^{\star *}$ \\
\hline
\end{tabular}

Fonte: INEP - Sinopses Estatísticas para os anos de 2003 a 2008 *Dado relativo exclusivamente à escola pública **Fonte: Jornal Folha de S. Paulo - 23/02/2010

Observe-se que, à medida que o ensino fundamental de nove anos vai sendo implementado, em especial a partir do ano de 2006, o número de reprovações das crianças na série inicial aumenta de forma expressiva. Cabe uma reflexão sobre o significado disso para a autoestima dessas crianças, para a organização pedagógica e didática desse ano de ensino e sobre as consequências de medidas como essa para as crianças e suas famílias. 0 indesejável fracasso escolar estaria começando mais cedo?
As hipóteses aventadas têm sido de que essas crianças foram reprovadas porque: 1) faltou qualidade no processo educativo para que elas pudessem progredir em suas aprendizagens e desenvolvimento; 2) os insumos para que o processo ensino-aprendizagem atendesse às necessidades de todas as crianças, promovendo-lhes a aprendizagem, foram insuficientes; 3) as redes de ensino e as instituições não respeitaram as diferenças e diversidades dessas crianças.

É evidente que a reprovação de crianças de 6 anos contraria os objetivos e pressupostos do 
ensino fundamental de nove anos apresentados nos documentos do MEC, além de contrariar o direito à educação estabelecido na CF/88 e na LDB/96. Isso indica a necessidade de a mesma ser revista a partir do estabelecimento das condições necessárias, em termos de quantidade e qualidade dos insumos, tal como preconiza a LDB/96, para a realização de uma educação que promova o desenvolvimento e a aprendizagem das crianças e elimine o recurso da reprovação para esconder as falhas dos sistemas de ensino. Nesse sentido, é preciso fazer valer a recomendação do Parecer CNE/CEB nº. 11, de 2010, que, ao estabelecer as Diretrizes Curriculares Nacionais para o Ensino Fundamental de Nove Anos, considera em seu $§ 1^{\circ}$ :

Mesmo quando o sistema de ensino ou escolas no uso de sua autonomia fizerem opção pelo regime seriado, será necessário considerar os três anos iniciais do Ensino Fundamental como um bloco pedagógico ou um ciclo sequencial não passível de interrupção, voltado para ampliar a todos os alunos as oportunidades de sistematização e aprofundamento das aprendizagens básicas, imprescindíveis para o prosseguimento dos estudos. (Brasil, 2010, grifo nosso)

Nossa pesquisa buscou conhecer a opinião de educadores sobre a adequação do currículo, do espaço físico e do preparo dos professores para trabalhar com o ensino fundamental de nove anos. Os entrevistados defenderam a formação continuada dos profissionais, a ampliação da discussão sobre o currículo (tanto para a nova turma que inicia o ensino fundamental quanto para as demais), assim como reformas e reorganização da estrutura física e material das escolas, enquanto aspectos necessários a uma implementação adequada. No entanto, não se constatou, na pesquisa, que qualquer uma dessas modificações estivesse sendo efetivamente realizada nas escolas.

Questionada sobre se a escola de ensino fundamental estava preparada para receber as crianças de 6 anos, uma professora afirmou:
[...] não, começando pela mobília, todos ficaram com os pés suspensos. É totalmente inadequado, alguns dependurados na carteira. A escola regular hoje está preparada para alunos maiores, ela não tem a característica de continuidade da infância. (Professora da rede estadual paulista)

A quase totalidade das professoras respondeu da mesma forma, argumentando que não houve adequação do espaço físico, reorganização do currículo e preparação dos professores. Em relação às entrevistas com os gestores, pôde-se perceber que há opiniões divergentes sobre esse tema. Para alguns, a escola de ensino fundamental tem condições de receber as crianças de 6 anos e atender as suas necessidades, principalmente se houver esforços por parte dos gestores e dos professores. Aqueles que responderam que a escola não tem condições de atender de forma adequada apresentaram como argumento a necessidade de os gestores e professores criarem espaços e formas diferenciadas de trabalhar pedagogicamente para minimizar o impacto que a criança de 6 anos terá ao entrar numa dinâmica de escolarização diferente do processo educativo realizado na pré-escola.

As entrevistas e questionários indicam que o currículo do primeiro ano do ensino fundamental reflete somente uma adaptação simplista do antigo currículo da primeira série, com pequenas adequações metodológicas para garantir momentos de brincadeiras, porém com limitações devido à ausência, nessas escolas, de espaços físicos que contemplem parques e brinquedotecas. Questionada se houve adaptações no currículo para trabalhar com as crianças de 6 anos, uma professora afirmou que não, e ponderou:

Nos últimos anos há uma preocupação maior com deixá-los um pouco mais livres pra brincar, mas também não pode ser muito porque nós temos metas pra atingir. Na essência, o trabalho é o mesmo. (Professora da rede municipal de São Paulo) 
A partir dessas ponderações, fica evidente que, para além da não reprovação, é importante que as escolas sejam contempladas com os recursos necessários, e os professores sejam orientados para a realização de um trabalho pedagógico com crianças entre 5 e 6 anos, agora no ensino fundamental com a idade entre 5 e 6 anos.

\section{À guisa de conclusões:}

a morte anunciada da pré-escola?

0 quadro que a pesquisa apresentou exige que se pondere sobre o papel histórico do atendimento da criança de 6 anos nas instituições de educação infantil e da importância das práticas pedagógicas específicas para as crianças pequenas. Diante das mudanças anunciadas e do processo de implantação verificado até então, é possível sustentar que o ensino fundamental de nove anos não representa, necessariamente, um ganho na educação das crianças pequenas. Ao contrário, diante das expectativas socialmente construídas pelos pais e pelas orientações e exigências das redes de ensino, muitas crianças de 6 anos têm sido submetidas a um regime de trabalho escolar incompatível com a faixa etária.

No atual contexto das políticas educacionais, é importante fazer as seguintes considerações sobre as crianças de 6 anos não serem mantidas nas escolas de educação infantil.

A luta histórica pelo reconhecimento da criança como "ser de direitos" (CF/88; Faria, 2002; Campos, Rosemberg, Ferreira, 1992; Kishimoto, 2001) e a construção do direito à educação infantil para as crianças de 0 a 6 anos de idade parecem estar sendo desconsideradas com a nova organização do ensino fundamental.

Em que pesem os limites da pesquisa ora apresentada, os dados podem ser compreendidos como um alerta acerca da tendência de nossa sociedade e, em certo sentido, das políticas educacionais exigirem de crianças, cuja principal demanda é o brincar, um esforço de adequação à disciplina dos tradicionais métodos da escola de ensino fundamental. Ao contrário do argumento de que as crianças de 6 anos trazem para o ensino fundamental uma dinâmica educativa mais atrativa às necessidades das crianças de 7 e 8 anos, os dados da primeira fase dessa pesquisa, considerando as falas dos entrevistados, indicam que a rotina da escola de ensino fundamental pouco foi alterada para receber esses novos alunos. Nesse sentido, não foram os anos seguintes que se modificaram; ao contrário, foi o novo primeiro ano que perdeu seu vigor e vivacidade.

As falas das professoras sobre a necessidade de realização de um trabalho que dê conta da alfabetização da criança ainda no primeiro ano parecem refletir o anseio dos pais e da sociedade em torno de uma alfabetização cada vez mais precoce, que desconsideram as diferenças culturais, sociais e de ritmo de aprendizagem das crianças. Menos do que oferecer oportunidade de desenvolvimento saudável e prazeroso às crianças brasileiras, essa organização escolar pode sugerir uma tentativa subliminar de acelerar ou reduzir os tempos da infância.

Nesse contexto, a meta do Movimento Todos pela Educação, de alfabetizar todas as crianças até 8 anos, pode ser entendida, num primeiro momento, como um avanço, mas em outro pode significar uma desconsideração às necessidades, especificidades e singularidades com as quais cada criança se relaciona com o mundo e se apropria da cultura socialmente produzida, principalmente quando disso decorrem propostas de se iniciar mais cedo o processo formal de alfabetização e letramento.

Se a aceitação dessa tese ganhar adeptos, em curto espaço de tempo poder-se-ia "dispensar" a passagem das crianças pela pré-escola, já que ali é um local de "brincadeiras", de contar e ouvir histórias, de comer gostoso, de descansar inventando sonhos, e a vida atual não permite mais essas utopias.

A Emenda Constitucional n. 59/09, apesar de sua pretensão de ampliar a duração da escolaridade obrigatória no Brasil para 14 anos, poderá trazer sérios problemas em relação ao provimento educacional para as crianças de 4 e 5 anos. Dado 
que já temos crianças entrando no ensino fundamental antes de completarem 6 anos, se não houver uma restrição radical à entrada das crianças de 5 anos no ensino fundamental, teremos, de forma inédita, a pré-escola com um ano ou, no máximo, um ano e meio de duração.

Atente-se que, de forma surpreendente e contraditória em relação às suas próprias orientações (Resolução CNE/CEB nº. 05/2009), o CNE autorizou, em 2010, pelo terceiro ano consecutivo, a manutenção das matrículas das crianças de 5 anos no ensino fundamental, quando ali estiverem sido matriculadas, caso tenham cursado dois anos de educação infantil.

É hora, portanto, de se superar a fragmentação da educação infantil, dividida equivocadamente em creches e pré-escolas, propondo com clareza a educação infantil de 0 a 5 anos e 11 meses, com possibilidade de ela ser realizada em uma só instituição educativa.

Se a intenção era tornar obrigatório o ensino a partir dos 4 anos de idade, por que não se ampliou o atendimento pré-escolar (dos 4 aos 6 anos) rumo a sua universalização nas escolas de educação infantil? Seria pertinente dizer que podemos estar ante a morte anunciada de uma das experiências educacionais mais exitosas no Brasil: a da educação infantil na faixa etária de 4 a 6 anos, que poderá encerrar sua existência em 2016.

Em nome da defesa de nossas crianças? Não. Em nome - mais uma vez - da (des)responsabilização do Estado pela educação das crianças dessa faixa etária. Se as políticas educacionais em nosso país continuarem a ser pautadas mais pelos interesses do capital e menos pelos propósitos de garantir o pleno desenvolvimento de toda criança, obrigar-se-á as crianças pequenas a abrirem mão das brincadeiras, da fantasia, do ócio criativo, dos desenhos, das pinturas, da poesia. Poesia, manifestação tão importante quanto a seriedade que a formalização dos estudos exige. 0 que diria Cecília Meireles, por meio de seu mosquito, sobre isso?

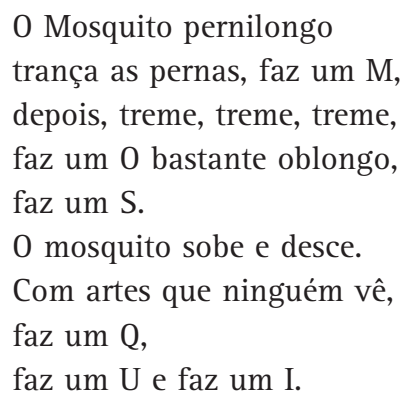

Cecília Meireles, “0 mosquito escreve”, in: $\mathrm{Ou}$ isto ou aquilo.

\section{Referências}

AMBROSETTI, N. B. Ciclo básico: uma proposta vista pelas professoras. Cadernos de Pesquisa, São Paulo (75), p. 57-70, nov. 1990.

ARELARO, L. R. G. Fundef: uma avaliação preliminar dos dez anos de sua implantação. Análise da 30ª REUNIÃO ANUAL DA ANPED, 2007. Disponível em: <http://www.anped.org.br/reunioes/30ra/index.htm>. Acesso em 30 set. 2010.

ARROYO, M. G. Ciclos de desenvolvimento humano e formação de educadores. In: Educação \& Sociedade, Campinas, v. 20, n. 68, p. 143-162, dez. 1999. 
AZEVEDO, J. C. Reconversão cultural da escola - mercoescola e escola cidadã. Porto Alegre: Sulina, Editora Universitária Metodista, 2007.

BENEVIDES, M. V. M. Cidadania e democracia. Lua Nova Revista de Cultura e Política, São Paulo, n. 33, p. 5-16, 1994.

BOBBIO, N. 0 futuro da democracia. São Paulo: Paz e Terra, 2000.

BRASIL. Constituição (1988). Constituição da República Federativa do Brasil: promulgada e publicada em 5 de outubro de 1988. São Paulo: Imprensa Oficial, 2001.

. Lei no. 9.394, de 20 de dezembro de 1996. Estabelece as diretrizes e bases da educação nacional. Diário Oficial [da] República Federativa do Brasil, Brasília, DF, 23 dez. 1996.

Emenda Constitucional nº. 14, de 12 de setembro de 1996. Modifica os arts. 34, 208, 211 e 212 da Constituição Federal e dá nova redação ao art. 60 do Ato das Disposições Constitucionais Transitórias. Disponível em: < http://www.planalto.gov. br/ccivil_03/constituicao/emendas/emc14.htm>. Acesso em 18 ago. 2010.

Lei $n^{\circ}$. 9.424, de 24 de dezembro de 1996. Dispõe sobre o Fundo de Manutenção e Desenvolvimento do Ensino Fundamental e de Valorização do Magistério, na forma prevista no art. $60, \S 7^{\circ}$, do Ato das Disposições Constitucionais transitórias, e dá outras providências. Disponível em: <http://www.pedagogiaemfoco.pro.br/19424_96.htm. Acesso em 18 ago. 2010.

. Ministério da Educação. Conselho Nacional de Educação. Câmara de Educação Básica. Parecer n . 22/98, aprovado em 17 de dezembro de 1998.

Lei $\mathrm{n}^{\circ}$. 10.172, de 9 de janeiro de 2001. Plano Nacional de Educação (PNE). Brasília: MEC, 2006. Disponível em: $<$ <ww.mec.gov.br>. Acesso em 18 jun. 2006.

. MEC/SEB. 0 ensino fundamental de nove anos: orientações gerais. Brasília: MEC/SEB, 2004a.

. Ampliação do ensino fundamental para nove anos: relatório do Programa. Brasilia: SEB/MEC, 2004b. Disponível em: $<$ www.mec.gov.br>. Acesso em 25 jul. 2010

Lei $n^{0} .11 .114$, de 9 de maio de 2005. Altera os arts. 60 30,32 e 87 da Lei no . 9.394, de 20 de dezembro de 1996, com o objetivo de tornar obrigatório 0 início do ensino fundamental aos seis anos de idade.

Ministério da Educação. Conselho Nacional de Educação. Câmara de Educação Básica. Resolução CNE/SEB nº 3, de 3 de agosto de 2005.

. Lei $n^{\circ}$. 11.274, de 6 de fevereiro de 2006. Altera a redação dos arts. 29, 30, 32 e 87 da Lei n’. 9.394 de 20 de dezembro de 1996, dispondo sobre a duração de 9 (nove) anos para o ensino fundamental, com matrícula obrigatória a partir dos 6 (seis) anos de idade.

. Ministério da Educação. Parâmetros Nacionais de Qualidade para Educação Infantil. Brasília: Secretaria de Educação Básica, v. 2, 2006.

Ensino fundamental de nove anos: orientações para a inclusão da criança de seis anos de idade. $2^{\mathrm{a}}$ ed. Brasília: FNDE, Estação Gráfica, 2007. 
Emenda Constitucional $n^{\circ}$. 59, de 11 de novembro de 2009. Disponível em: <http://www.planalto.gov.br/ccivil_03/ constituicao/emendas/emc59.htm>. Acesso em 18 ago. 2010.

Ensino fundamental de nove anos: passo a passo do processo de implantação. 2ª. ed. Brasília: Ministério da Educação, set. 2009.

MEC. Portaria nº .777 , de 10 de agosto de 2009. Aprova a Resolução da Comissão Intergovernamental de Financiamento para a Educação Básica de Qualidade para o exercício de 2010.

. Conselho Nacional de Educação. Parecer nº. 7, de 7 de julho de 2010. Estabelece as Diretrizes Curriculares Nacionais para o Ensino Fundamental de Nove Anos. Brasília, 2010.

. Ministério da Educação. Instituto Nacional de Estudos e Pesquisas Educacionais Anísio Teixeira (Inep). Censo Escolar. Sinopse Estatística dos anos de 2003 a 2008.

CAMPOS, M. M.; ROSEMBERG, F.; FERREIRA, I. M. Creches e pré-escolas no Brasil. São Paulo: Cortez, 1992.

CORRÊA, B. C. A educação infantil. In: OLIVEIRA, R. P.; ADRIÃO, T. (orgs.). Organização do ensino no Brasil. São Paulo: Xamã, 2002.

COSTA. V. L. C. Descentralização da educação - novas formas de coordenação e financiamento. São Paulo: Fundap/ Cortez, 2000.

FARIA,A. L. G. Educação pré-escolar e cultura: para uma pedagogia da educação infantil. $2^{\mathrm{a}}$ ed. Campinas: Cortez/Unicamp, 2002.

FOLHA DE SÃO PAULO. São Paulo, 23 fev. 2010. Disponível em: <http://www1.folha.uol.com.br/fsp/cotidian/ff2302201007.htm>. Acesso em 21 set. 2010.

JACOMINI, M. A. Educar sem reprovar. São Paulo: Cortez, 2010.

KISHIMOTO, T. M.. A LDB e as instituições de educação infantil: desafios e perspectivas. Revista Paulista de Educação Física, São Paulo, v. 4, p. 7-14, 2001.

Recebido em: 30.09.2010

Aprovado em: 10.12.2010

Lisete Regina Gomes Arelaro é professora titular da Faculdade de Educação da USP. Realiza pesquisas na área de política educacional, gestão de sistemas e financiamento da educação.

Márcia Aparecida Jacomini é professora do curso de Licenciatura Plena em Ciências da UNIFESP - Campus Diadema. Realiza pesquisa na área de política educacional e gestão escolar. E-mail: marciajacomini@uol.com.br

Sylvie Bonifácio Klein é Coordenadora Pedagógica da Rede Municipal de Ensino de São Paulo. Mestranda na linha de pesquisa Estado, Sociedade e Educação da Faculdade de Educação da USP. E-mail: sylviebk@hotmail.com 